schools, probably tied to a long series of suggestions regarding nutrition and physical activity provided by teachers and parents, even if the incidence of hypertension remain high. There is an evident need to better monitor the consumption of alcoholic drinks and salty foods.

Funding: Research relating to this abstract was funded by the Institute of Social Affaires.

\title{
49 - Obesity and hypertension today in comparison to past years
}

\author{
A Spagnolo ${ }^{1}$, P Musacchio $^{2}$, V Austini ${ }^{1}, G$ Colavecchi $^{1}$ and E Menghetti ${ }^{1}$ \\ 'ISFOL ex Institute of Social Affaires, Rome, Italy: ${ }^{2} \mathrm{UOCI}$ Mother and Child ASL RMD, Rome, Italy
}

\begin{abstract}
Introduction: We wanted to compare the past situation regarding the prevalence of obesity and hypertension in Italy, above all in Rome, with the current situation in the City of Rome in order to verify eventual changes that have occurred following the issuing of suggestions by experts on a correct diet and better physical activity.

Methods: Two thousand forty-five children between the ages of 6 and 17 years in three Italian cities (Varese, Rome, Catanzaro) were compared with about 700 children in Rome aged 10-12 years. The first study was carried out in 2005-2008, the second in 2010. In both studies the heightweight measurement was carried out in accordance with data collection criteria, while for the second study the measure of blood pressure was done using OMRON2, calibrated with the mercury sphygmomanometer used in the earlier study.
\end{abstract}

The diagnoses of obesity and hypertension was made using the same standards in both studies: Cole and coll. for obesity and the TASK FORCE table for hypertension.

Results: In the first study $6 \cdot 1 \%$ of the sample was obese $(6 \cdot 1 \%$ in Rome) while $19 \cdot 8 \%$ were obese $(21.7 \%$ in Rome); taken together $5 \cdot 5 \%$ had hypertension $(3 \cdot 1 \%$ in Rome). In the second study, the more recent one, $3 \cdot 3 \%$ were obese $(23 \cdot 1 \%$ were overweight) and $7 \cdot 8 \%$ had hypertension.

Conclusion: We can affirm that obesity has decreased in the last few years (in terms of stationary overweight children) while hypertension has increate. It is probable that the continuous nutritional suggestions to increase the intake in fruit, vegetables and fish have brought results while it is necessary to fight to reduce the consumption of salt and alcoholic drinks.

Conflict of Interest: None.

Funding: Research relating to this abstract was funded by Institute of Social Affaires.

\section{0 - The influence of lifestyle on obesity and arterial hypertension}

\author{
A Spagnolo' ${ }^{1}$ P Musacchio ${ }^{2}$, L Tawill ${ }^{3}$, AM Gabrielli ${ }^{2}$ and E Menghetti ${ }^{1}$ \\ ${ }^{1}$ ISFOL ex Institute of Social Affaires, Rome, Italy: ${ }^{2}$ UOCI Mother and Child ASL RMD, Rome, Italy: ${ }^{3}$ IDI Hospital, \\ Reparto Pediatrico, Rome, Italy
}

Introduction: Evaluate the attention paid by the family and minors to correct nutritional habits, physical activity and lifestyle changes in recent years.

Method: Two questionnaires, completed both by parents and minors, were used to gather data. The study included 381 males and 312 females from five schools in
Rome during the 2009-2010 school year. The weight, height and blood pressure were measured for each minor. The questionnaires included a series of questions regarding eventual reductions in the consumption of past, condiments and fats $v$. an increase in the intake of fruit, vegetables and fish. The questions also focused 